\title{
Ogoh-Ogoh Dan Implementasinya Pada Kreativitas Berkarya Seni Rupa Tiga Dimensi
}

\author{
Made Aditya Abhi Ganika ${ }^{1}$ I Wayan Suardana ${ }^{2}$ \\ ${ }^{1,2}$ Pendidikan Seni, Pascasarjana, Universitas Negeri Yogyakarta, Jl. Colombo No.1, Karang Malang, Catur- \\ tunggal, Kec. Depok, Kabupaten Sleman, Daerah Istimewa Yogyakarta 55281
}

abhiganika@gmail.com

Penelitian ini bertujuan mendeskripsiskan Estetika eksperimental Ogoh-ogoh dan mendeskripsikan hasil implementasi Ogoh-ogoh pada kreativitas berkarya seni rupa tiga dimensi. Jenis penelitian ini adalah deskriptif kualitatif penelitian mendeskripsikan penciptaan Ogoh-ogoh pada rangkaian hari raya Nyepi tahun 2018 di Pura Jagatnatha, Sorowajan, Banguntapan, Bantul, DIY. Implementasu teknik penciptaan di laksanakan pada pembelajaran seni rupa tiga dimensi di SMK BOPKRI 1 Yogyakarta, Terban, Gondokusuman. Data di kumpulkan melalui observasi, wawancara mendalam dan dokumentasi. Hasil penelitian menunjukan: (1) Ide penciptaan Ogoh-ogoh di mulai dari studi pustaka tentang Upacara Hari Raya. Penciptaan meliputi tahapan membuat rancangan sketsa Ogoh-ogoh, membuat kerangka dengan menggunakan bahan dari besi atau kayu yang berfungsi sebagai penyangga Ogoh-ogoh kemudian membentuk rangka dasar dengan menggunakan styrofoam atau bambu, melapisi rangka body menggunakan kertas agar body Ogoh-ogoh mudah untuk diwarna menggunakan cat. dengan bentuk mata melotot, gigi tajam, badan besar yang merupakan tanda keberadaan sifat-sifat jahat dalam diri manusia. (2) Tema konsep dan teknik Penciptaan Ogoh-ogoh di implementasikan pada pembelajaran seni rupa tiga dimensi di SMK BOPKRI 1 Yogyakarta. Peserta didik menciptakan bentuk patung dengan teknik butsir dengan media tanah liat.

Kata kunci : estetika, eksperimental, kreativitas, ogoh-ogoh, seni rupa tiga dimensi

\section{Ogoh-Ogoh Experimental Aesthetics and Its Implementation in Creativity in Three Dimensional Fine Arts}

This study aims to describe the experimental aesthetics of the Ogoh-ogoh statue and describe the results of the implementation of Ogoh-ogoh on the creativity of working in three-dimensional art. This type of research is a qualitative descriptive research describing the creation of Ogoh-ogoh on the series of Nyepi holidays in 2018 at Jagatnatha Temple, Sorowajan, Banguntapan, Bantul, DIY. The implementation of the creation technique was carried out in the learning of three-dimensional art in Yogyakarta BOPKRI 1, Terban, Gondokusuman. Data collected through observation, in-depth interviews and documentation. The results of the study show: (1) The idea of creating Ogoh-ogoh starts from the literature study on the holiday ceremony. The creation process includes the stages of making a sketch design of Ogoh-ogoh, making a framework using materials from iron or wood that serves as a buffer for Ogoh-ogoh then forming a base frame using styrofoam or bamboo, coating the body frame using paper so that the Ogoh-ogoh body is easy to color use paint. with bulging eyes, sharp teeth, large bodies that are a sign of the existence of evil characteristics in humans. (2) The theme of the concept and technique of Ogoh-ogoh Creation was implemented in the learning of three-dimensional art in SMK BOPKRI 1 Yogyakarta. Students create a sculpture shape with butsir technique with clay media.

Keywords: aesthetics, experimental, creativity, ogoh-ogoh, three-dimensional art 


\section{PENDAHULUAN}

Pulau Bali mayoritas masyakatnya beragama Hindu terkenal dengan tradisi dan budaya dengan kekuatan adat istiadat dan spiritual. Agama Hindu sebagai agama tertua mempunyai berbagai sisi baik dari segi budaya (Madrasuta, 2004:9). Kebudayaan Bali menjunjung tinggi keseimbangan dan harmonisasi kehidupan. Pandangan terhadap ajaran Tri Hita Karana yang menyatakan tiga penyebab terciptanya kebahagiaan. Tri Hita Karana menjelaskan hubungan manusia dengan Tuhan (parahyangan), hubungan sesama manusia (pawongan), dan hubungan manusia dengan lingkungan (palemahan). Falsafat ini didukung dengan perayaan hari raya Nyepi.

Ogoh-ogoh merupakan salah satu konsep trihita karna dibuat menyerupai boneka raksasa menggunakan paduan panca warna yang sangat impresif dan menakjubkan: merah, putih, hitam, kuning dan poleng. Pada akhirnya kegitan acara Ogoh-ogoh dibakar (Pralina) agar unsur-unsur Panca Maha Bhuta (api, air, tanah, udara dan cahaya) kembali ke asalnya. Secara simbolik upacara itu menggambarkan dunia yang kembali berada dalam keseimbangan sinergi hidup dan kehidupan di alam semesta. Ogoh-ogoh banyak memunculkan makna simbol-simbol yang tertuang dalam kearifan lokal upacara adat menjelang hari raya Nyepi. Pada perkembangan jaman Ogoh-ogoh berinovasi dengan bentuk dan teknik dalam penciptaannya. Ogoh-ogoh berkembang semakin inovatif pada kerangkanya dibuat dengan menggunakan besi. Pembungkus badan Ogoh-ogoh diganti dengan gabus. Tema Ogoh-ogoh semakin bervariasi dari tema pewayangan, modern, sampai politik yang tidak mencerminkan makna agama. Tema Ogoh-ogoh yang tampil tetap mencerminkan nilai agama Hindu yang tidak lepas dari Tuhan, manusia dan Bhuta Kala. Ogoh-ogoh sebagai simbol Bhuta Kala sesuai dengan sastra agama merupakan penerapan kreativitas anak muda yang mengeksploitasi bentuk gejala alam dan fenomena sosial yang terjadi di masyarakat saat ini sehingga tidak ada pembatasan ataupun pengekangan untuk berekspresi.

Penelitian ini bertujuan untuk mendeskripsikan serta menganalisis estetika eksperimental Ogoh-ogoh dan mengimplementasikannya melalui penciptaan Ogoh-ogoh sebagai upaya pengembangan kreativitas berkarya seni rupa tiga dimensi di SMK BOPKRI 1 Yogyakarta. Tahapan implementasi ini bukan untuk mencari makna dari simbol agama Hindu melainkan untuk berproses dan berkarya seni rupa tiga dimensi dengan inspirasi karya Ogoh-ogoh pada mata pelajaran seni budaya di SMK BOPKRI 1 Yogyakarta.

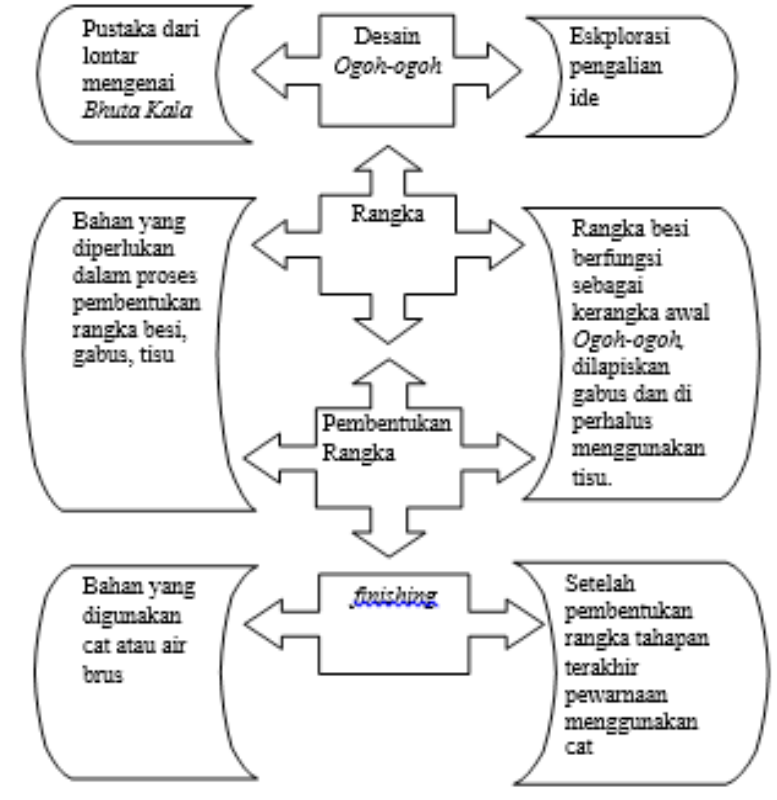

Skema Proses Penciptaan Ogoh-ogoh

\section{METODE PENELITIAN}

Penelitian ini jenis metode kualitatif yang diuraikan dengan cara deskriptif memeroleh data dan fakta tentang (1) estetika eksperimental Ogoh-ogoh, (2) implementasi penciptaan Ogoh-ogoh terhadap kreativitas berkarya seni rupa. Penelitian ini menggunakan fenomenologis Sumarto (2017:49) Pendekatan fenomenologi mendeskripsikan esensi umum pengalaman seseorang menghadapai fenomena tertentu (Van Mean, 1990: 177; Creswell, 2007: 57-58). Lokasi penelitian ini yaitu di Pura Jagatnatha yang terletak di Desa Plumbon Banguntapan, Bantul, Yogyakartayang dilaksanakan pada proses penciptaan karya dan dilanjutkan prosesi pengarakan Ogoh-ogoh yang dilaksanakan di Candi Prambanan dan Malioboro.

Sumber data yang digunakan pada penelitian ini terdiri dari sumber data primer dan sumber data sekunder. Sumber data primer yaitu data yang diperoleh dari pengamatan langsung terhadap proses pembuatan karya Ogoh-ogoh dan hasil wawancara dengan para narasumber yaitu masyarakat Hindu yang berpartisipasi pembuatan Ogoh-ogoh di Pura Banguntapan, Yogyakarta dan hasil karya siswa SMK BOPKRI 1 Yogyakarta, sedangkan data sekunder dilaksanakan pada penelitian terdahulu pada penciptaan Ogoh-ogoh. Data yang didapat disajikan dan menjadi hasil penelitian. Analisis digunakan pada penelitian adalah metode deskriptif dengan mendeskripsikan secara mendalam apa yang terjadi pada prosesi upacara $O g$ oh-ogoh di Yogyakarta dan mengimplementasikan pada proses berkarya seni rupa tiga dimensi di SMK 
BOPKRI 1 Yogyakarta. Dan diklasifikasikan dianalisis dan diuraikan kembali secara sistematis

\section{ANALISIS DAN INTEPRETASI DATA}

Proses terjadi penciptaan patung Ogoh-ogoh ada beberapa aspek untuk diperhatikan dan disimak menciptakan patung Ogoh-ogoh. Tiga tahap yang menjadi rambu-rambu membuat dan menciptakan patung Ogoh-ogoh. Tahap pertama, eksplorasi atau penggalian atau pencarian ide. Pada proses tahapan pencipta Ogoh-ogoh mengeksplorasi pada bagian cerita tokoh Mahabrata, Ramayana, dan Calonarang cerita yang diangkat pada lontar-lontar yang menginterpertasikan Bhutakala. Gambaran ide muncul dari hasil eksplorasi. Tahapan kedua, tahapan eskperimentasi merupakan perancangan patung Ogoh-ogoh. Selanjutnya tahap ketiga adalah proses membuat bentuk diawali dengan menyiapkan bahan-bahan dan material Ogoh-ogoh alat-alat yang diperlukan untuk tahapan pembentukan bagian dasar adalah tahapan perangkaan badan dan tahapan bagian tangan kaki dan muka selanjutnya tahapan pewarnaan dan terakhir tahapan penataan atribut atau pepayasan dan tahapan akhir yakni proses penyelesaian akhir.

\section{Estetika Eksperimental Patung Ogoh-ogoh}

Penciptaan patung Ogoh-ogoh tidak lepas dari ekspresi estetika yang dipengaruhi oleh beberapa faktor diantaranya adalah: (1) idiologi awal pencipta Ogoh-ogoh; yang berupa ide pencipta Ogoh-ogoh dan memberi arah objektivikasi berdasarkan pengetahuan proses penciptaan, selajutnya pengetahuan proses penciptaan diarahkan menentukan dari bentuk keindahan Ogoh-ogoh. Pemikiran awal ini memberikan wujud bentuk sehingga dapat memperoleh tingkat, jenis, serta bentuk pemikiran awal ini menjadi pusat menentukan bentuk atau simbol berikutnya. (2) Pikiran yang memberikan arah pada kehadiran ilmu pengetahuan yang sudah mantap atau sudah terbentuk. Proses ini memperoleh pemikiran sehingga dapat menyusun sturktur sistem untuk menentukan bahan objektivikasi menjadi simbol atau icon yang diinginkan. (3) Pemikiran dari pengetahuan tersebut yang secara terpaksa harus menentukan bentuk barunya disinilah muncul eksperimental proses penciptaan patung Ogoh-ogoh. Proses inilah yang menjadi sebuah bentuk baru yang disebut dengan subjek karya seni.

Nilai estetika yang muncul dari penampilan suatu penciptaan Ogoh-ogoh yang terletak pada bentuk yang ekspresif, bentuk patung Ogoh-ogoh dapat berperan sebagai: simbol, ikon dan tanda suatu pesanan. Keterkaitan bentuk dengan pesanan ini menyebabkan konsep estetika intensity (kesungguhan) bentuk menjadi tergiring dengan tujuan informatif (Monroe
Beardsley Dharsono, 2007: 63). Nilai estetika $O g$ oh-ogoh yang dimaksudkan adalah ungkapan keindahan: menangkap pesan dan memvisualkan bentuk sesuai dengan imajinasi serta ekspresi di

\section{Analisis Ogoh-ogoh dengan Teori Semiotika}

Tabel 1. Bentuk dan konsep penciptaan ogoh-ogoh
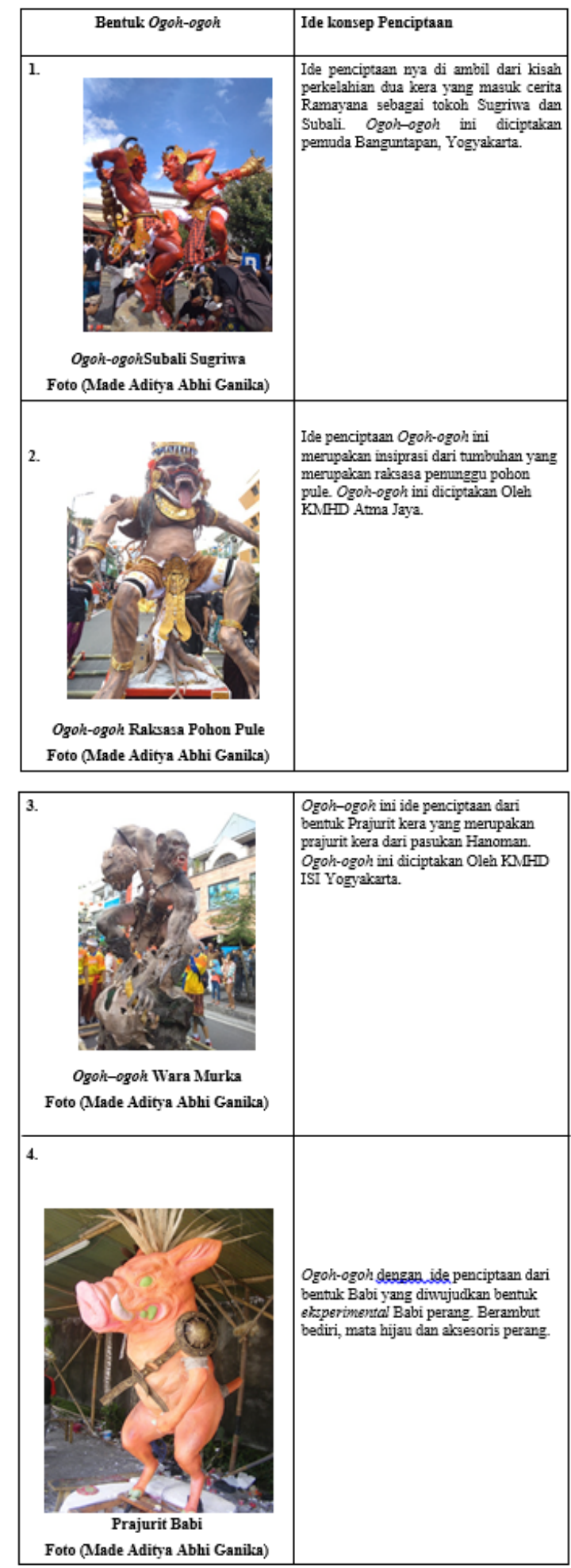


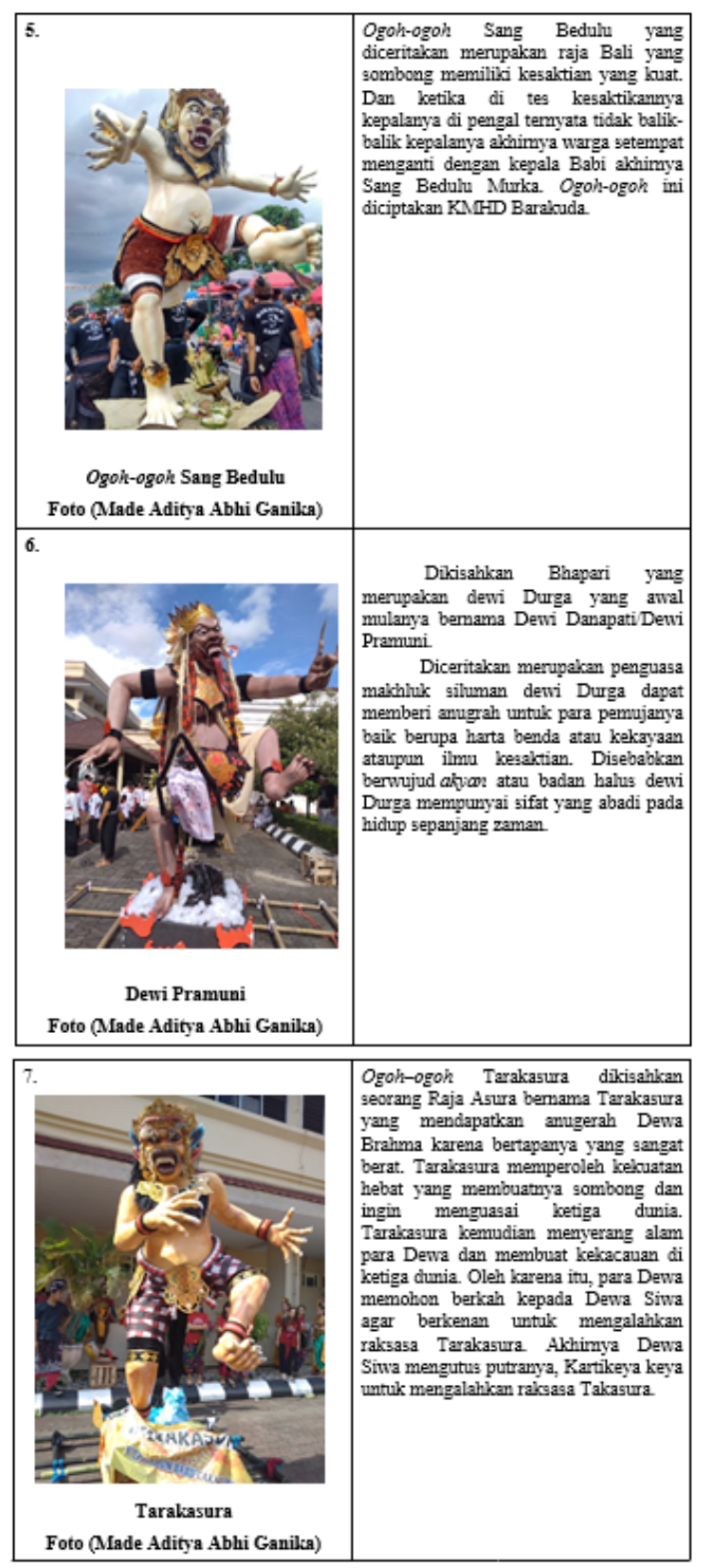

\begin{tabular}{|c|c|c|c|c|}
\hline No & Ikon & Indeks & Simbol & \begin{tabular}{|l} 
Sifat Positif \\
(terpuji) dan \\
Sifat Negatif \\
(tercela) \\
\end{tabular} \\
\hline 1. & $\begin{array}{l}\text { Ogoh-ogoh } \\
\text { Sugriwa dan Subali }\end{array}$ & \begin{tabular}{|l|} 
Sugriva dan \\
Subali yang \\
gedang bertarung
\end{tabular} & \begin{tabular}{|l} 
Subali dan \\
Sugriva di \\
simbolkan \\
wujud kera \\
yang sedang \\
bertarumg kama \\
kesalah \\
pahaman
\end{tabular} & $\begin{array}{l}\text { Sifat sugriwa } \\
\text { dan Subali } \\
\text { termasuk } \\
\text { gifat Krodha: } \\
\text { kemarahan }\end{array}$ \\
\hline 2. & $\begin{array}{l}\text { Ogoh-ogoh Raksasa } \\
\text { Pohon Pule }\end{array}$ & \begin{tabular}{|l|} 
Memiliki watah \\
yang nafsu \\
banyak keinginan \\
dan rakus
\end{tabular} & \begin{tabular}{|l} 
Disombolkan \\
bentuk Raksasa \\
yang memiliki \\
mata melotot, \\
gigi bertaring, \\
berbaddan \\
besar, bagign \\
bawwah berisikan \\
ranting pohon \\
\end{tabular} & $\begin{array}{l}\text { Sifat yang } \\
\text { terksapung } \\
\text { ajaran Hindu } \\
\text { termasuk sifat } \\
\text { Kama. }\end{array}$ \\
\hline 3. & \begin{tabular}{|l} 
Ogoh-ogoh \\
Waramurka
\end{tabular} & \begin{tabular}{|l|} 
Ogoh-ogoh yang \\
merupakan \\
prajurit kera yang \\
gedang marah.
\end{tabular} & $\begin{array}{l}\text { Disimbolkan } \\
\text { bentuk kera } \\
\text { yang memegang } \\
\text { batu Gigi } \\
\text { bertaring, mata } \\
\text { tatapan tajam, } \\
\text { berwama coklat } \\
\end{array}$ & \begin{tabular}{|l|} 
Sifat yang \\
terkandung \\
Ogoh-ogoh \\
Waramurka \\
gifat Moha
\end{tabular} \\
\hline 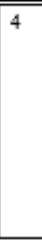 & $\begin{array}{l}\text { Ogoh-ogoh Prajurit } \\
\text { Babi. }\end{array}$ & \begin{tabular}{|l|} 
Ogoh-ogoh \\
Prajurt babi yang \\
bermatat hijau, \\
rambut berdiri, \\
gigi tajam \\
berwama putith, \\
yang \\
beratributkan \\
akesoris perang. \\
\end{tabular} & $\begin{array}{l}\text { Bentuk Babi } \\
\text { yang di } \\
\text { sisuallasan. } \\
\text { bentukogos } \\
\text { ogoh perang } \\
\text { merupakan } \\
\text { gimbollkan dari } \\
\text { Babi yang } \\
\text { mempunyai } \\
\text { kehuatan. } \\
\end{array}$ & 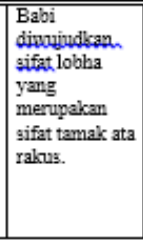 \\
\hline 5. & $\begin{array}{l}\text { Ogoh-ogoh Sang } \\
\text { Bedulu. }\end{array}$ & \begin{tabular}{|l|} 
Ogoh-ogoh sang \\
bedulu di \\
kisahkan raja Bali \\
yang sombong \\
yang di tes \\
kesaktiannya \\
tetapi kepala nya \\
tidak balikk-balik \\
lalu diganti kepala \\
Babi.
\end{tabular} & 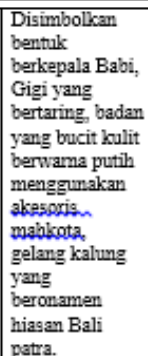 & \begin{tabular}{|l} 
Sang Bedulu \\
menupakan \\
raja yang \\
Sombong \\
yang \\
termasuk. Sad \\
Ripu sifat \\
Mada yang \\
tergolong \\
sombong.
\end{tabular} \\
\hline 6 & $\begin{array}{l}\text { Ogoh-ogoh Dewi } \\
\text { Pramumi. }\end{array}$ & \begin{tabular}{|l|} 
Dewi Pramuni \\
yang bertapa \\
karena keinginan \\
nya menikahi \\
Sanghyang \\
Manikmaya, raja \\
Tribhurwana \\
akhirnya karena \\
keinginan \\
menjelma menjadi \\
Durgha.
\end{tabular} & 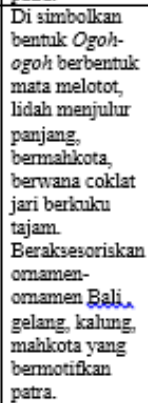 & \begin{tabular}{|l} 
Dewi Pramuni \\
tergolong \\
gifat \\
Kanayang \\
memiliki \\
Keiinginan
\end{tabular} \\
\hline 7. & Ogoh-ogoh Takarura & 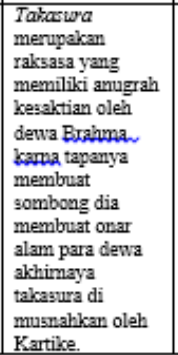 & $\begin{array}{l}\text { Di simbollkan } \\
\text { dengan bentuk } \\
\text { mata melotot, } \\
\text { alis tebal, badan } \\
\text { besar dan perut } \\
\text { buncit. }\end{array}$ & $\begin{array}{l}\text { Takaswar } \\
\text { tergolong } \\
\text { sifat Magda } \\
\text { merupakan } \\
\text { gifat } \\
\text { sombong. }\end{array}$ \\
\hline
\end{tabular}


Simbol yang terkandung dalam Ogoh-ogoh dianailis dengan menggunakan teori semiotika Carles Sander Peirce yaitu "ikonik, indeksikal dan simbol."

Nilai Pendidikan yang terkandung dalam simbolisasi Ogoh-ogoh ada tiga faktor yang menentukan adanya sebuah tanda, Yustina (2013:103) 1) tanda itu sendiri, 2) hal yang ditandai dan 3) sebuah tanda baru diterima dari batin si penerima. Tokoh Ogoh-ogoh merupakan sebuah tanda karena mempunyai kesamaan dengan watak enam musuh yang berada diri manusia. Bagian-bagian sad ripu meliputi:
1. Kama
: nafsu, keinginan
2. Lobha
: tamak, rakus
3. Krodha
: kemarahan
4. Moha
5. Mada
: kebingungan
: sombong
6. Matsarya : dengki, iri hati

Kama yang dimaksud sad ripu ini adalah nafsu atau keinginan yang negatif. Hal ini Raksasa Pohon Pule termasuk sifat Kama karena memiliki watah yang nafsu banyak keinginan dan rakus. Maka dari itu sifat Kama yang disimbolakan pada Ogoh-ogoh raksasa Pohon Pule sifat ini harus dilebur dari diri manusia agar bias menggendalikan nafsunya. Lobha berarti tamak atau rakus yang sifatnya negatif sehingga merugikan orang lain. Lobha yang sifatnya negatif akan menyebabkan seseorang terdorong untuk melakukan kejahatan karena merasa tidak pernah puas dengan apa yang dimilikinya. Sifat lobha di simbolkan bentuk Ogoh-ogoh Prajurit Babi memiliki watak lobha yang harus di lebur agar manusia bias menahan sifat-sifat negatif yang merugikan orang lain. Sifat krodha disimbolkan bentuk Ogoh-ogoh Sugriwa dan Subali yang tidak bisa mengendalikan amarahnya akibatnya membunuh sodarnya sendiri sifat Krodha harus dilebur diri manusia agar dapat mengendalkan amarah dan tidak menyebabkan kerugian pada diri sendiri ataupun orang lain. Sifat Moha disimbolkan bentuk Ogoh-ogoh Wara Murka yang kebingungan tidak bias berfikir jernih sifat-sifat ini harus di lebur. Watak Mada disimbolkan bentuk $O g$ oh-ogoh sang bedulu dan Takasura yang memiliki sifat sombong yang harus dihilangkan diri manusia. Ogoh-ogoh diciptakan pada bentuk Raksasa atau bentuk yang mewakilkan sifat sadripu ini harus di lebur dengan cara Ogoh-ogoh yang dibuat perayaan pengerupukan hari raya Nyepi wajib untuk di bakar sebagai simbol keenam sifat yang ada diri manusia itu harus dilebur.

\section{Implementasi Kreativitas Berkarya Seni Rupa Tiga Dimensi}

Berikut tahap penciptaan Ogoh-ogoh yang dilaksanakan di SMK BOPKRI 1 Yogyakarta tahapan mulai dari apresiasi bentuk Ogoh-ogoh dan mengkreasikan bentuk Ogoh-ogoh. Siswa mengapresiasi bentuk

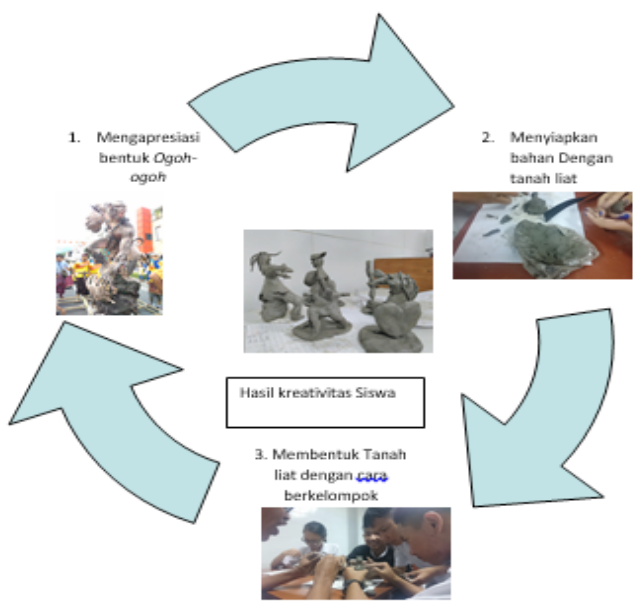

Ogoh-ogoh seperti bentuk Raksasa pada cerita-cerita Ramayana, Mahabarata dan raksasa yang berbentuk hewan. Siswa berkreasi dan bereksperimen bentuk sesuai dengan imajinasi mereka dengan tema $O g$ oh-ogoh. Menyiapkan bahan dengan tahan liat berfungsi sebagai bahan yang mudah dibentuk oleh anak. Menggunakan tanah liat berjenis lempung yang bewarna abu-abu. Setelah menyiapkan bahan, anak memulai membentuk tanah liat dengan berkelompok berfungsi untuk melatih kerjasama anak agar sosial mereka lebih berkembang. Hasil karya siswa dalam menciptakan hasil kreativitas membentuk ini cukup berhasil. Di lihat dari bentuk bentuk yang berani di ambil oleh anak ketika anak dibebaskan untuk membuat bentuk sesuai dengan imajinasi mereka. Dan eksperimen terhadap bentuk-bentuk ini merupakan tahapan terjadi kreativitas pada perkembangan otak anak.

Membentuk patung Ogoh-ogoh dapat meningkatkan aspek kemampuan kognitif siswa dapat mengembangkan kreativitas dan kemampuan berpikir siswa. Kreativitas berkaitan dengan aktivitas belahan otak kanan. Oleh sebab itu, intuitif dan imajinatif merupakan aspek lain yang mempengaruhi munculnya kreativitas. Kreativitas dipengaruhi oleh aspek kemampuan melakukan pengindraan, yaitu kemampuan menggunakan panca indra secara peka. Kepekaan pengindraan ini menyebabkan seseorang dapat menemukan sesuatu yang tidak dapat dilihat atau diperkirakan oleh orang lain. Maka dari itu proses apresiasi mengamati bentuk Ogoh-ogoh ini penting untuk meningkatkan kepekaan pengindraan siswa dan menghargai karya seni. Aspek kreasi berfungsi untuk meningkatkan kecerdasan emosi siswa berkaitan dengan cara membentuk patung Ogoh-ogoh.

\section{SIMPULAN}

Bertolak dari hasil analisis penelitian terhadap estetika eksperimental Ogoh-ogoh dapat diimplementasi 
pada penciptaan Ogoh-ogoh terhadap kreativitas berkarya seni rupa di Yogyakarta dapat disimpulkan:Pertama, Estetika eksperimental Ogoh-ogoh merupakan Ogoh-ogoh eksperimental mempunyai peran sebagai nilai estetika yang muncul dari penciptaan Ogoh-ogoh adalah bentuk yang ekspresif. Kedua, Ogoh-ogoh memiliki implementasi terhadap kreativitas berkarya seni rupa tiga dimensi. Kreativitas membentuk $O g$ oh-ogoh memiliki fungsi untuk menghasilkan ide mengkreasikan bentuk Ogoh-ogoh menjadi bentuk yang baru. Dari segi bentuk dan bahan yang digunakan banyak mengalami perubahan. Kemampuan untuk menghasilkan banyak ide yang keluar dari pemikiran seseorang secara cepat.

\section{DAFTAR RUJUKAN}

Creswell, J. W., \& Plano Clark, V. L. Designing and Conducting Mixed Methods Research. Thousand Oals, CA: Sage, 2007.

Fox, Howard. (1987). Avant Garde in the Eighties, dalam The Post-Avant Garde: Painting in the Eighties, ed. Charles Jencks. Academy Edition. London.

Gie, The Liang, "Filsafat Seni (Sebuah Pengantar)", Yogyakarta: Penerbit Pubib, 1976.

Norman K dan Lincoln. (2009). Handook of Qualitativ Research. (Terjemahan Dariyanto, Badrus Fata, Abi, John Rinaldi) California. (buku asli diterbitkan 2000).

Madrasuta, Ngakan Made. (2004). Hindu Agama Terbesar Di Dunia. Media Hindu:Jakarta.

Misriyanti, Ayu (2016). Simbol Gambar Patung Ogoh-ogoh Pada Warga Transmigrasi Suku Bali Di Desa Sumber Jaya Kecamatan Lalembu Kabupaten Konawe Selatan. Jurnal Ilmu Komunikasi UHO. Retrieved http://ojs.uho.ac.id/index.php/KOMUNIKASI/article/view/1602

Sumarto, (2017). Metodologi Penelitian Kualitatif Seni Rupa \& Desain. Pusat Studi Rancangan Visual dan Lingkungan Fakultas Seni Rupa dan Desain. Universitas Trisakti. Jakarta. 